\title{
Autonomia e formação humana em situações pedagógicas : um difícil percurso
}

Maurício Mogilka

Universidade Federal do Paraná

\section{Resumo}

Este artigo desenvolve uma discussão sobre o processo de estruturação da autonomia da criança em situações pedagógicas. Inicia buscando fazer a distinção entre os conceitos de liberdade e autonomia, posto que freqüentemente tomados como sinônimos. Estabelecer esta distinção é fundamental para explicitar o caráter não inato da autonomia, qualidade do ser que precisa de estruturação.

Na abordagem teórica escolhida para esta discussão, de caráter interacionista, a estruturação da autonomia é encarada como um processo que precisa ser construído, entre a liberdade natural, inerente à natureza humana, e a capacidade da criança se auto-regular, na relação com as necessidades de seus semelhantes. Este processo é considerado aqui como resultante de um diálogo entre as potencialidades inatas da criança e os elementos externos ao seu eu: a cultura e as relações sociais. Quando esta interação não é coercitiva e nem permissiva, dar-se-iam as condições necessárias para a estruturação saudável do eu, isto é, o processo de formação humana, entendida no sentido mais rigoroso e pleno de positividade.

A reflexão desenvolvida é fundamentada na pedagogia humanista, especialmente no pensamento de Rousseau, Rogers e Dewey. 0 texto conclui com uma visão positiva sobre as possibilidades de construção da autonomia, mas tenta mostrar, dentro dos seus limites e do seu horizonte teórico, que esta é uma possibilidade problemática. Isto se daria pela dificuldade do agir e do compreender democráticos em uma sociedade simultaneamente diretiva e permissiva.

\section{Palavras-chave}

Educação democrática - Autonomia - Pedagogia humanista Natureza humana.

80060-150 - Curitiba - PR 


\title{
Autonomy and human development in pedagogical situations : a difficult journey
}

Maurício Mogilka

Universidade Federal do Paraná

\begin{abstract}
This article discusses the process of structuring the child's autonomy in pedagogical situations. It starts by attempting to distinguish between the concepts of freedom and autonomy, since these are often taken synonymously. It is fundamental to establish this distinction to reveal the non-innate character of the autonomy, a quality of the being that needs structuring. In the interactionist theoretical approach chosen for this discussion the structuring of autonomy is seen as a process that needs to be built between the natural freedom - inherent to human nature - and the self-regulating ability of the child in the face of the needs of her/his equals. This process is considered here as resulting from a dialogue between the child's innate potentials and elements external to his/her self: the culture and the social relations. When such interaction is neither coercive nor lax the necessary conditions would be given to a healthy structuring of the self, that is, the process of human formation understood in its most rigorous sense and full of positiveness.

The reflection developed here is rooted in the Humanist pedagogy, especially in the thinking of Rousseau, Rogers, and Dewey. The text concludes with a positive view of the possibilities of constructing autonomy but, within the limits and theoretical boundaries of the work, tries to show that this is a problematical possibility. That would be due to the difficulty of acting and comprehending democratically in a society that is simultaneously conducive and permissive.
\end{abstract}

\section{Key words}

Democratic education - Autonomy - Humanist pedagogy Human nature.

Correspondence:

Rua General Carneiro, 460

80060-150 - Curitiba - PR

e-mail:

mauricio@educacao.ufpr.br 
Os abipones, por um costume recebido dos seus ancestrais, fazem tudo de acordo com sua vontade e não de acordo com a de seu cacique. Cabe a mim dirigi-los, mas eu não poderia prejudicar nenhum dos meus sem prejudicar a mim mesmo; se eu utilizasse as ordens ou a força com meus companheiros, logo eles me dariam as costas. Prefiro ser amado e não temido por eles (relato do chefe guerreiro Alaykin, nação Abipone, chaco argentino; citado por Clastres, 1990).

Koyaanisqatsi (da língua hopi, América do Norte): 1. A vida enlouquecida. 2. A vida em estado de inquietação ou confusão. 3. A vida em desintegração. 4. A vida em desequilíbrio. 5. Um estado vital que exige outro modo de viver (do filme de Godfrey Reggio, Koyaanisqatsi - a vida em desequilíbrio).

\section{Da liberdade à autonomia}

É muito comum, na Pedagogia e nos discursos produzidos nas escolas, que as palavras liberdade e autonomia sejam tomadas como sinônimos. Esta coincidência conceitual acaba por produzir dificuldades no tratamento das questões sobre práticas democráticas, pois estas palavras não significam a mesma coisa, pelo menos não integralmente. 0 termo liberdade significa irrestrição, o estado no qual o agente encontra espaço para agir, pensar e desejar sem contenção ou impedimento, realizando aquilo que lhe é necessário ou aquilo que ele quer. 0 termo autonomia, derivado dos vocábulos gregos auto (próprio) e nomos (lei ou regra), significa a capacidade de definir as suas próprias regras e limites, sem que estes precisem ser impostos por outro: significa que aquele agente é capaz de se auto-regular. Logo, na palavra autonomia estão implícitos, simultaneamente, a liberdade relativa do agente, que pode prescindir de um poder externo que o regule, e a limitação, derivada necessariamente da relação com o mundo natural e social.
A questão que está sendo proposta neste estudo é a seguinte: uma prática pedagógica pode possibilitar às crianças e jovens a estruturação da sua autonomia, no contexto atual de uma sociedade capitalista? Tem uma prática tal poder e tal possibilidade? Ou será a educação uma prática necessariamente fundamentada na coerção, como pensava Kant? Pode a educação ser uma prática aberta à liberdade? Se refletirmos sobre esta questão, e procurarmos sentir a sua densidade, veremos que o que está em discussão é a própria possibilidade da liberdade humana, aqui neste pequeno texto analisada em uma situação específica - a pedagógica - apenas por uma necessidade de recorte do tema, para tornar possível a reflexão. Em outras palavras, não há uma liberdade social e uma liberdade pedagógica, distintas e separadas, mas trata-se do mesmo fenômeno, em situações diferentes.

Um aspecto muito problemático da questão aqui colocada é que ao falarmos de educação para a autonomia, não podemos esquecer que a criança, em processos iniciais de socialização, está simultaneamente formando a si mesma e sendo formada por estes processos. Ela age sobre aquilo que a forma, e se tem um certo grau de liberdade em suas escolhas, permitido pela sua natureza, ela nunca tem todo o controle sobre estes processos, mesmo os mais próximos ao seu corpo. Essa dialética entre a criança e aquilo que é externo ao seu eu é que nos permite compreender o seu desenvolvimento e estruturação, sem cair em posições empiristas e nem idealistas.

Mesmo com uma tendência natural para a liberdade - com vocação para a liberdade, como defende a pedagogia humanista esta tendência inata não está estruturada. A criança precisa, paradoxalmente, de um elemento externo, de uma relação com a autoridade, para estruturar, para atualizar aquilo que lhe é inato. Parece, portanto, um equívoco opor liberdade à ação do adulto junto à 
criança, como se a criança só pudesse ser livre se estiver sozinha. A criança vive no mundo e com o mundo. A liberdade, tendência inata, só pode se estruturar em-relação: ela precisa do outro e da cultura para se estruturar. De potência a ato, nós precisamos do mundo. 0 grande problema não seria, me parece, a ação do adulto junto à criança, porque esta ação é inevitável, não há humanização sem relação social e sem cultura. 0 problema seria, na verdade, a natureza dessa relação.

Estes dois elementos externos à criança a relação social e a cultura - com os quais ela precisa se relacionar para ser aquilo que ela é, contudo, estão estruturados em formas de poder. Não há vida fora do poder, e este pode ser uma força construtiva, nós já aprendemos isto com Nietzsche e com Foucault. Logo, e dialeticamente, a criança precisa da autoridade para estruturar a sua liberdade. 0 problema central aqui é a natureza deste poder com o qual a criança precisará se relacionar necessariamente, pois a liberdade não pode estruturar a si mesma, sem recorrer aos elementos externos ao eu da criança: sem uma relação consciente com os limites não há autonomia. Se a liberdade é uma tendência inata do organismo humano - de qualquer forma de vida, aliás - que precisa se relacionar com limites para se estruturar em-relação, nós nos defrontamos então com uma questão critica: quem define os limites? Com que propósitos? Até que ponto um certo limite, colocado para a criança, deriva de uma relação necessária com o meio natural e social, ou na verdade esconde em seu bojo interesses de exploração e conquista do eu? Em uma sociedade como a nossa, os limites são definidos resguardando que tipo de interesse, e de quem?

\section{Liberdade e natureza}

Se considerássemos que a criança tem apenas, inicialmente, o aparato neurológico e as estruturas físico-químicas e sensóriomotoras que servirão de base ao processo de formação do eu, através da ação da cultura e das relações sociais, a questão seria bem mais simples. Formada de fora para dentro, essencialmente, a sua autonomia seria conseqüência desse processo formativo, que permitiria, em maior ou menor grau, um certo espaço para a criança se auto-regular e se auto-determinar. 0 problema é que todo ser autônomo possui um senso de escolhas, e nunca é completamente previsível o seu comportamento.

Então, como um elemento externo ao eu pode fornecer a imprevisibilidade? Como uma formação, que se realiza através de elementos definidos, pode prover o indefinido, se ele já não for uma capacidade inata da criança? A autonomia implica um comportamento que sempre apresenta um certo grau de incerteza, instabilidade e indeterminação, a não ser que expliquemos o comportamento humano como algo previsível, cuja previsibilidade é decorrente de determinações externas ao sujeito, decorrentes das estruturas da vida material e social, como a concepção acima exposta, ou, ao contrário, de uma racionalidade constituidora do real.

Embora eu respeite as reflexões destas concepções e seus defensores, eu penso de forma bem diversa, pois me parece que elas dão pouca ênfase à ação da criança e às suas potencialidades inatas no seu processo de formação. Na minha percepção, muito mais próxima do interacionismo da pedagogia humanista, é no jogo complexo, conflitivo e às vezes, tenso, entre as potencialidades inatas, a ação da criança e a importante contribuição da cultura e das relações sociais que se dá o indeterminado e instável processo de formação humana. Em pleno século XX, a pedagogia humanista buscou, através de seus diversos autores, explicar o comportamento humano dotado de certo grau de imprevisibilidade somente explicável a partir de uma tendência inata do organismo humano para a liberdade. 0 ser humano possui um senso de 
escolhas livre e responsável, que lhe permite um elenco de respostas aos estímulos do ambiente, maior do que se dispusesse apenas do instinto e de aprendizagens primárias (Rogers, 1978).

$\mathrm{Na}$ pedagogia e na psicologia humanistas, o ser humano é entendido como um organismo complexo, onde são indissociáveis mente, corpo e sociedade, isto é, ele é um ser bio-psico-social. Além da tendência inata para a liberdade, o ser humano é visto como possuindo uma tendência natural para a realização, o bem-estar e o crescimento. Ele é intrinsecamente motivado, e deseja crescer e aprender sempre mais sobre o seu ambiente e sobre si mesmo (Rogers, 1978, 1981, 1985). A pedagogia humanista fundamenta esta concepção positiva do ser humano em diferentes matrizes filosóficas, como o pragmatismo norte-americano, a fenomenologia e o existencialismo. Contudo, uma referência do século XVIII praticamente atravessa toda a pedagogia humanista: trata-se do pensamento de Jean-Jacques Rousseau.

Várias reflexões do pensamento rousseauísta serão fundamentais para a constituição da pedagogia humanista nos fins do século XIX e durante todo o século XX. Contudo, dois conceitos são mais importantes para o tema deste estudo: o conceito de estado natural e a idéia de que as desigualdades sociais não são derivadas, intrínseca e necessariamente, da natureza humana. Rousseau define o estado da natureza como aquilo que a pessoa é, antes de qualquer processo de socialização. Em tal estado hipotético, não há o desejo de domínio sobre o outro, e tampouco comportamentos que degradem a própria natureza do indivíduo. É um estado sadio, embora limitado pelas condições que o meio-ambiente oferece e pelo pouco desenvolvido aparato psíquico (Rousseau, 1978a, 1978b).

0 caminho seguido por Rousseau é problemático. Primeiro porque não há ser humano antes da socialização: os casos de crianças que cresceram sem o contato humano, como as meninas-lobo na Índia e o garoto selvagem descoberto pelo Dr. Itard, na França do século XIX, mostraram como essas crianças não mostravam comportamentos humanos, mas fortemente instintivos. Em segundo lugar, ao contrário do afirmado por Rousseau em seu raciocínio hipotético-dedutivo, o ser humano não é naturalmente tendente à vida solitária, mas inatamente gregário. Não há sequer uma cultura humana onde os indivíduos vivam isolados, como já nos mostrou a antropologia. Contudo, Rousseau não dispunha, no século XVIII, de suficientes evidências para perceber isto com a clareza que temos hoje.

Apesar destas contradições, e sustentado por um raciocínio brilhante, o que Rousseau legou ao século XIX, neste ponto específico do seu pensamento, foi uma concepção positiva de ser humano, e uma crítica rigorosa a uma sociedade que corrompe o estado natural. Rousseau defende que o ser humano possui naturalmente dois princípios, anteriores à razão: uma tendência à auto-conservação e uma busca do próprio bem-estar, e uma rejeição natural à morte ou sofrimento de qualquer ser sensível, especialmente seus semelhantes (Rousseau, 1978a). 0 homem não é, portanto, o lobo do homem: a competição e o domínio são aprendidos socialmente, e a tendência natural do ser humano é pela compaixão, e não pela destruição do outro:

...seus deveres para com outrem não lhe são unicamente ditados pelas lições tardias de sabedoria, e enquanto resistir ao impulso interior natural da comiseração, jamais fará qualquer mal a um outro homem, nem mesmo a um ser sensivel, exceto no caso legítimo em que, encontrando-se em jogo sua conservação, é obrigado a dar preferência si mesmo. (Rousseau, 1978a, p.231)

Da mesma forma como não é naturalmente destrutiva ao ser do outro, a pessoa humana também não possui uma tendência 
natural à servidão. 0 estado natural é um estado de liberdade, e é somente após séculos de domínio que se pode entender o comportamento submisso dos civilizados, que tanta indignação causa a Rousseau. Freqüentemente interpretamos um fenômeno apenas por aquilo que vemos, sem perceber que ele poderia ser diferente daquilo que é: atribuímos qualidades a ele, quando na verdade elas são contingenciais, isto é, históricas, e não essenciais. Rousseau nos mostra como atribuímos à pessoa humana uma tendência natural à servidão, pois vemos em nossa sociedade um grande contingente de pessoas se acomodarem à sua falta de liberdade. Esquecemos que só se percebe o valor da liberdade quando a usufruímos, e que perdemos o seu gosto quando não a temos na prática.

0 autor recorre a um outro argumento para provar a tese segundo a qual o ser humano possui uma tendência natural para a liberdade. A submissão dos civilizados não pode ser tomado como indício de uma suposta tendência à servidão, pois a luta dos povos não-civilizados para conservar a liberdade demonstra como este bem lhes é importante:

Não é pois pelo aviltamento dos povos dominados que se devem julgar das disposições naturais do homem a favor ou contra a servidão, mas sim pelo prodígio realizado por todos os povos livres para se defenderem da opressão. Sei que os primeiros nada fazem senão enaltecer continuamente a paz e o sossego de que gozam sob seus grilhões e que chamam de paz à mais miserável das servidões, mas quando vejo os outros sacrificarem os prazeres e o repouso, a riqueza, o poder e a própria vida pela conservação deste único bem tão desprezado por aqueles que o perderam (...) concluo não poderem ser os escravos os mais indicados para raciocinar sobre a liberdade. (Rousseau, 1978a, p.272-273)

Rousseau tem clareza que nem a liberdade, nem a compaixão, nem o respeito pela vida do outro se sustentariam se não possuíssem uma base natural, isto é, se fossem desenvolvidas apenas pela razão, pela cultura e pela socialização, especialmente em uma sociedade de classes. Há muito tempo a espécie humana teria perecido, se a sua conservação dependesse apenas da aprendizagem social e da razão.

\section{Um interacionismo arrojado}

Embora freqüentemente acusada de idealista e subjetivista, a pedagogia humanista, ao menos nos autores aqui utilizados, se revela, após um exame mais acurado, uma concepção de caráter interacionista. Nela a criança é vista como um ser ativo capaz de atuar sobre o ambiente, ao mesmo tempo que está continuamente sofrendo influências deste ambiente natural e social. É precisamente desta interação que nasce a experiência humana. Isto é bem visível nas palavras de Dewey:

Quando se diz que uma pessoa vive em uma série de situações, o sentido da palavra em é diferente do seu sentido quando dizemos que o dinheiro está em um cofre, ou a tinta em uma lata. Significa, repetimos, que há interação entre o indivíduo, objetos e outras pessoas. Os conceitos de situação e interação são inseparáveis um do outro. Uma experiência é o que é, porque uma transação está ocorrendo entre o indivíduo e o seu meio. (...) 0 meio ou ambiente é formado pelas condições, quaisquer que sejam, em interação com as necessidades, desejos, propósitos e aptidões pessoais de criar a experiência em curso. Mesmo quando a pessoa imagina castelos no ar, está em interação com os objetos que sua fantasia constrói. (Dewey, 1979b, p.36-37)

Em interação constante com o meio ambiente e com o social, é através desta interação que a criança se forma. Na perspectiva interacionista, se considera que a criança necessita do meio para sua formação, pois ela 
não tem todas as chaves de sua constituição. Mas, simultaneamente, ela não é uma tabula rasa, um conjunto de estruturas orgânicas e neurológicas sobre as quais a cultura e a relação social vão trabalhar para "produzir" o sujeito. Ela é entendida como um organismo incompleto, porém pleno de possibilidades: já possui desejos, interesses e capacidades. Contudo, muitas de suas capacidades e faculdades inatas não estão estruturadas. É através da ação da criança, da cultura e da relação social que é possível à criança estruturar aquilo que ela já traz, e que demanda expansão. Não é, porém, qualquer ação pedagógica que será capaz de promover esta estruturação. Para desenvolver, estruturar, formar positivamente, fazer desabrochar, que são os significados originais do termo educação (educere), a ação pedagógica precisa exercer uma autoridade que seja estruturante, mas não seja coercitiva, não promova a inibição ou constrangimento de um processo que é simultaneamente interno e externo à criança.

0 poder constitui a própria vida, mas nem toda forma de poder estrutura, desenvolve, contribui para a formação da individualidade. 0 poder coercitivo, por exemplo, se expressa através da coibição, repressão, contenção. É próprio à natureza da coerção, segundo o significado do termo, impedir, obstruir, bloquear a manifestação de um fenômeno. Se verificamos esse poder na prática, vemos que é precisamente essa a natureza da ação a que denominamos coerção, de tal forma que não se trata aqui de um mero jogo de palavras. Parece haver, portanto, uma incompatibilidade entre o exercício da coerção e a estruturação da autonomia da criança, entendida esta como derivada, ao menos inicialmente, de uma tendência inata da criança para a liberdade. A única maneira, me parece, de sustentar a compatibilidade entre coerção e estruturação para a autonomia seria considerar a formação da criança como um processo basicamente de fora para dentro, e não um processo interativo.
A pedagogia humanista, tanto em Dewey como em Rogers, considera que uma ação pedagógica só é efetivamente democrática, isto é, estrutura para a autonomia, quando se baseia, desde o seu início, no interesse genuíno, na necessidade e na motivação intrínseca da criança. Estas são as molas propulsoras de qualquer prática não-coercitiva, pois a criança se engaja pelo desejo, na medida em que consegue, através dessa prática, perceber que está realizando as suas demandas de expansão e crescimento. 0 trabalho educativo com crianças pequenas nos mostra que elas percebem suas necessidades de crescimento e aprendizagem, mesmo que não consigam expressar isto conceitualmente de forma muito clara. É justamente quando o processo pedagógico não foi montado a partir das necessidades e interesses da criança, que surgem as dificuldades para o seu engajamento nas atividades. Aí, freqüentemente, a escola lança mão de medidas coercitivas para cativar uma atenção que não obteve espontaneamente. Neste jogo de poder, dificilmente se estrutura a autonomia.

Rogers nos mostra como a motivação intrínseca é preexistente ao processo de socialização. A escola tradicional desperdiça o grande potencial que ela representa, pois aproveitá-la implicaria rever os currículos e a organização da escola, que não são montados levando em conta a vida real do estudante:

Fico irritadíssimo com a idéia de que o estudante deve ser "motivado". 0 jovem é intrinsecamente motivado, em alto grau. Muitos elementos de seu meio ambiente constituem desafios para ele. É curioso, tem a ânsia de descobrir, de conhecer, de resolver problemas. 0 lado triste da maior parte da educação está em que, após a criança haver passado anos e anos na escola, essa motivação intrínseca está muito bem amortecida. Mas continua a existir, e nossa tarefa, como facilitadores de aprendizagem, é a de suscitar essa motivação, 
descobrir que desafios são reais para o jovem e proporcionar-lhe a oportunidade de enfrentá-los. (Rogers, 1978, p.134-135)

Em um ensaio publicado em 1913, Dewey mostra a forte contradição entre coerção e o desenvolvimento de uma verdadeira disciplina:

Porque, já não há quem possa negar, a doutrina da disciplina imposta falhou. É absurdo supor que uma criança conquiste mais disciplina mental ou intelectual ao fazer, sem querer, qualquer coisa, do que fazê-la, desejando-a de todo o coração. (Dewey, 1980b, p.153)

Contudo, Dewey alerta que a chamada teoria do interesse - tornar um assunto interessante pelo tratamento dado a ele, sem mudar a sua natureza - também é prejudicial, pois recorre a artifícios que não tornam o conteúdo realmente interessante para a criança. Além disto, tende a enfraquecer seu caráter e sua vontade, pois submete o trabalho pedagógico aos seus impulsos imediatos, na tentativa de cativar artificialmente sua atenção. Com isto, corre-se o risco de contribuir na formação de jovens prepotentes e inconstantes, porque desconectados do seu próprio eu e incapazes de auto-disciplina.

Na pedagogia da escola nova não há, portanto, uma proposta espontaneísta (no pior sentido da palavra), como argumentaram alguns dos seus críticos. 0 que se propõe, na realidade, é desenvolver e direcionar a natureza da criança, tornando-a gradualmente consciente das necessidades do mundo adulto, e não submeter o processo pedagógico a esta natureza, pois aí não se completaria o que está, pela natureza, apenas dado inicialmente. Aliás este princípio já está bem claro em Rousseau (1996), quando este autor defende a necessidade de educar a criança pela atividade orientada, evitando deixá-la à sua própria sorte (pois nem tudo está dado pela natureza, Rousseau é bem consciente disto). Mas evitando também opri- mir as tendências, aptidões e necessidades infantis, pois estas são o ponto de partida de qualquer formação sadia.

Para Dewey, tanto a pedagogia do esforço como a pedagogia do interesse são problemáticas, pois provocam dissipação de atenção e de energia, ao criar uma situação didática em que a criança é levada a prestar atenção, pela força da disciplina imposta ou por algum artifício, uma vez que aquele assunto ou atividade não lhe interessa realmente. Isto ocorre porque ambas as concepções não resolveram um problema crucial, que é a identificação necessária entre o sujeito e o objeto da ação pedagógica. Para isto, é necessário rever a questão, o que implica recolocar o conceito de interesse:

0 legítimo princípio do interesse, entretanto, é o que reconhece uma identificação entre 0 fato que deve ser aprendido ou a ação que deve ser praticada e o agente que por esta atividade se vai desenvolver. Aquele fato ou ação se encontra na direção do próprio crescimento do agente, que os reclama imperiosamente para se realizar a si mesmo. Assegure-se esta identificação ou correspondência entre o objeto e o agente, e não teremos que recorrer aos bons ofícios da "força de vontade", nem nos ocupar de "tornar as coisas interessantes. (Dewey, 1980b, p.155)

Se é necessário aproximar o conhecimento e a atividade escolar dos interesses da criança, não são contudo quaisquer interesses que conduzem a uma prática educativa, mas somente aqueles que atendem às suas necessidades de aprendizagem e desenvolvimento. Caso contrário, a prática escolar pode perder a sua identidade, deixando de atender, necessariamente, ao desenvolvimento infantil. É justamente essa escolha seletiva dos interesses da criança, que possuam algum caráter educativo, que faz a pedagogia da escola nova, pelo menos em autores como Dewey, se 
constituir em uma proposta viável e sempre atual. 0 conhecimento desse princípio também põe por terra, definitivamente me parece, a crítica segundo a qual trabalhar com os interesses e motivações intrínsecas da criança, e montar a partir daí o currículo e o método, tornariam a prática escolar incapaz de promover a aprendizagem de conhecimentos e habilidades necessárias à cidadania.

Iniciar um processo de aprendizagem pelos interesses da criança não significa limitar o processo a estes interesses, pois eles podem ser ampliados. Contudo, tal processo de formação não pode ignorar interesses e desejos como seu ponto de partida, a não ser que se lance mão da coerção e da manipulação - mas aí se sacrificam as possibilidades de uma formação democrática. Fazer esta distinção entre interesses educativos e não-educativos e conduzir o processo em sintonia com as necessidades da criança exige dos profissionais da escola sensibilidade, respeito à liberdade e consciência dos limites que precisam ser negociados e estabelecidos. Esse cuidado é essencial para que a prática não se transforme em mera recreação, pois na escola o lúdico precisa estar associado ao educativo, isto é, aquilo que desenvolve e estrutura.

Para Dewey, a atividade é inerente ao ser vivo. É só através da ação que ocorre a estruturação e desenvolvimento das funções e potencialidades humanas. Contudo, há uma indissociabilidade entre interesse e atividade, uma vez que o interesse tem um caráter ativo ou propulsivo, ele nunca é passivo, sempre tende a engajar a criança em uma ação que satisfaça as necessidades associadas àquele interesse. Desta forma, em um organismo sadio, a atividade nunca é vã, é sempre atividade em direção a algum objetivo ou interesse: "Onde houver vida há atividade, e qualquer atividade tem sempre alguma tendência ou direção própria” (Dewey, 1980b, p.160). 0 interesse leva à ação, e algumas ações conduzem à estruturação do eu. Por isto, toda atividade pedida pela escola deve se conectar, ao menos inicialmente, a um interesse já existente na criança. Isto não impede que esses interesses possam ser ampliados ao longo do tempo.

Se toda atividade sadia está associada a um interesse genuíno, certas atividades são fundamentais para o desenvolvimento das potencialidades da criança que demandam expansão, naquele momento. Daí ficam claros dois equívocos da educação escolar, seja a tradicional seja aquela baseada em uma equivocada teoria do interesse: a escolha dos conteúdos independentemente dos interesses e necessidades da criança, e a redução do método de ensino a artifícios externos de preparação do material, a fim de despertar sua atenção. Nos dois casos, dada a separação entre o espírito da criança e o objeto do conhecimento, o método de ensino passa a ser a tentativa de preencher o vazio causado por esta separação. Contudo, isto constitui um empreendimento muito fragilmente obtido, seja por coerção, seja por artifícios, uma vez que não se resolveu a gênese do problema: a concepção dualista entre sujeito e objeto.

Ao contrário, e baseado no princípio do interesse educativamente legítimo - aquele que expressa as necessidades de desenvolvimento da criança - o educador deve buscar na seleção dos assuntos e na escolha dos métodos e do material de ensino, uma íntima conexão com as necessidades, forças e experiências da criança, seja de forma direta ou indireta. Em outras palavras: o problema será o de descobrir a relação intrínseca entre a matéria, ou o objeto, e a pessoa, relação esta que, uma vez conscientemente percebida, passa a ser o motivo da atenção (Dewey, 1980b, p.162).

Se atividade e interesse são indissociáveis em um organismo sadio, também disciplina e interesse não podem - não poderiam - ser entendidos separadamente. Segundo Dewey (1979b), uma das mais nocivas conseqüências da filosofia tradicional da educação, tanto na 
sua vertente mais empirista quanto inatista, foi consagrar o dualismo entre sujeito e mundo, mente e objeto. Entendendo-se o espírito da criança e a matéria de estudo como coisas separadas, temos como conseqüência uma concepção negativa de disciplina, ao invés de identificá-la com a capacidade de realização. A noção de que a mente da criança constitui uma entidade completa em si mesma, sem vínculo necessário com o objeto do conhecimento, torna a disciplina um mero esforço, a capacidade de dirigir a atenção para alguma coisa externa, apenas pelo exercício da força de vontade. Quanto mais desinteressante, quanto mais distante dos interesses da criança for aquela matéria ou atividade, maior será o seu valor disciplinador, já que a relação estará baseada apenas na capacidade de dominar as paixões.

Para Dewey, interesse e disciplina são fenômenos conexos, e não opostos. Uma criança desenvolve a auto-disciplina porque está interessada nos objetivos daquela atividade, precisa deles para estruturar suas capacidades nascentes. Ela percebe, com a ajuda do educador, que precisa aprender a direcionar a atenção e a energia para alcançar tais objetivos. Se isto não ocorre, qualquer atividade realizada através da disciplina imposta - externa ou internalizada - não consegue esconder o fato de que há uma distância entre a criança e o objeto da sua ação. Neste caso, ou este objeto não contribui para a estruturação da criança, e portanto seu uso não é educativo, ou esta contribuição não foi conscientemente percebida pela criança. Neste último caso, é necessário que o educador ajude a criança a perceber a conexão, e então a disciplina surge como conseqüência desta percepção.

A ação seletiva do educador com relação aos interesses e desejos manifestados pela criança, discutida anteriormente, põe em relevo a importância do outro para a constituição da autonomia da criança, isto é, a importância da intersubjetividade no desenvolvimento ético. Em Dewey, esta constituição é estruturada fora de padrões moralistas, conformistas ou tradicionais, mas não cai em um exercício irresponsável da liberdade, que contraria a sua própria viabilidade. 0 autor tem uma percepção clara da importância da experiência do adulto para a formação da criança. Uma educação democrática, baseada no aproveitamento da experiência pessoal e social, que é a referência mais significativa que a criança tem, implica na rejeição do controle externo arbitrário, mas não no abandono de qualquer tipo de autoridade.

Ao contrário, deve-se buscar fonte mais efetiva de autoridade, nascida dos contatos entre a experiência da criança, que é respeitada e aproveitada, e a orientação do adulto. Nesta perspectiva não-impositiva, tal orientação pode ser mais bem utilizada pela criança, pois a mesma não se sente constrangida, tem um maior espaço para opções e se relaciona em um clima sócio-emocional mais positivo, estando aberta à orientação do adulto. Através deste tipo de interação, mais íntimo e afetivo do que o contato frio e severo do paradigma tradicional, gera-se mais e melhor direcionamento e orientação à criança, sem recorrer ao autoritarismo nem à manipulação (Dewey, 1979a). Quando a criança aceita esta orientação, isto ocorre não por qualquer respeito a normas ou deveres sociais, mas porque ela sente que a experiência do adulto está ampliando a sua própria experiência, e tornando-a mais capaz de viver e conviver.

A estruturação da autonomia passa por uma etapa na qual é imprescindivel o contato com a autoridade, com as necessidades do outro e com os limites que estas necessidades geram. A liberdade pessoal só se realiza quando situada em relação ao contexto e ao outro: isto é a autonomia. Este é um dos maiores problemas da relação autoritária: ela não fornece à criança esta experiência instável e delicada em que ela se relaciona com um poder que lhe é externo, mas que não oprime sua própria força, e lhe permite balizar o seu 
próprio exercício de liberdade e de limitação. De forma diferente, mas com efeito semelhante, a relação permissiva também não favorece a estruturação da autonomia, pois aí a criança não tem referências em que se apoiar para sentir os seus limites. Não se trata de práticas democráticas, pela sua omissão. Democracia, em um sentido radical do termo, não significa 0 não-exercício da autoridade, mas uma forma específica de exercê-la (Mogilka, 2000).

Vida é poder, mas quando este poder é coercitivo, ele se volta contra a vida, constrangendo-a ao invés de realizá-la. Esta é a fonte do desequilíbrio. 0 poder coercitivo é o suporte subjetivo de toda sociedade baseada na desigualdade social e na dominação. Para que uma educação democrática se realize, é preciso que a prática pedagógica se converta em prática educativa, permitindo a estruturação da autonomia da criança no próprio processo, e não somente nos objetivos e fins mais amplos da educação. Isto dificilmente se dá sob coerção. Demonstrar tal possibilidade foi a intenção deste estudo.

\section{Referências bibliográficas}

CLASTRES, Pierre. A sociedade contra o estado: pesquisas de antropologia política. Rio de Janeiro: Francisco Alves, 1990.

COUSINET, Roger. A educação nova. Lisboa: Moraes, 1976.

DEWEY, John. Como pensamos. Como se relaciona o pensamento reflexivo com o processo educativo: uma reexposição. São Paulo: Nacional, 1959.

Experiência e educação. São Paulo: Nacional, 1979a. Democracia e educação: introdução à filosofia da educação. São Paulo: Nacional, 1979b. A criança e o programa escolar. São Paulo: Abril Cultural, 1980a. (Os pensadores) Interesse e esforço. São Paulo: Abril Cultural, 1980b. (Os pensadores)

FOUCAULT, Michael. A microfísica do poder. Rio de Janeiro: Graal, 1992. Vigiar e punir. Petrópolis: Vozes, 1987.

KANT, Imanuel. Pedagogía. Madrid: Akal, 1983.

MOGILKA, Maurício. A mudança consentida: um estudo sobre a postura do professor diante da mudança em seu trabalho. Revista da FAEEEBA, Salvador, n.8, p.90-110, jul./dez. 1997. [no prelo] Relações afetivas: articulações entre subjetividade e educação democrática. São Paulo, 2000.

ROGERS, Carl. Liberdade para aprender. Belo Horizonte: Interlivros, 1978. Liberdade de aprender em nossa década. Porto Alegre: Artes Médicas, 1985. Um jeito de ser. São Paulo: EPU, 1983. Tornar-se pessoa. São Paulo: Martins Fontes, 1991. Sobre o poder pessoal. São Paulo: Martins Fontes, 1992. 
ROUSSEAU, Jean-Jacques. Discurso sobre a origem e os fundamentos da desigualdade entre os homens. São Paulo: Abril Cultural, 1978a. (Os pensadores)

Do contrato social: princípios de direito político. São Paulo: Abril Cultural, 1978b. (Os pensadores). Emílio ou da educação. São Paulo: Martins Fontes, 1996.

Recebido em 27 jun. 2000

Aprovado em 12 set. 2000

Maurício Mogilka é professor de Didática na Universidade Federal do Paraná. Desenvolve trabalhos na área que compreende a relação entre práticas educativas, formação humana e cidadania. Na extensão universitária, trabalha com capacitação de educadores sociais, crianças em situação de risco, organização do trabalho comunitário e geração de práticas alternativas na educação popular. 